\title{
RESISTÊNCIA INTER E INTRA-AGREGADOS EM ENSAIOS DE CISALHAMENTO DIRETO DE UM NITOSSOLO VERMELHO DISTRÓFICO ${ }^{(1)}$
}

\author{
João Alfredo Braida ${ }^{(2)}$, José Miguel Reichert ${ }^{(3)}$, José Mário Doleys \\ Soares $^{(4)} \&$ Dalvan José Reinert ${ }^{(3)}$
}

\begin{abstract}
RESUMO
Para solos agregados, a envoltória da resistência ao cisalhamento pode ser dividida em dois segmentos, com declividades e interceptos diferentes. Um primeiro segmento mais inclinado e com intercepto menor representaria a envoltória de ruptura definida pelo atrito e coesão interagregados, enquanto o segundo segmento, menos inclinado e com intercepto maior, seria a envoltória definida pelo atrito e coesão intra-agregados. O presente estudo foi realizado com o objetivo de avaliar se a envoltória de resistência ao cisalhamento de agregados do horizonte superficial de um Nitossolo Vermelho pode ser subdividida em segmentos distintos, com coeficientes angulares diferentes, e se isso está relacionado à existência de agregados nele. Inicialmente, amostras coletadas na superfície de um Nitossolo Vermelho distrófico latossólico de textura argilosa foram submetidas ao ensaio de cisalhamento direto com pressões normais de 24,$4 ; 48,9 ; 98,2 ; 196,4$; 294,6; 392,8 e 491,8 kPa. Posteriormente, o ensaio foi realizado com amostras de agregados de cinco classes de diâmetro: < 0,25; 0,25-0,50; 0,50-1,00; 1,00-2,00 e 2,00$4,00 \mathrm{~mm}$, empregando-se pressões normais de 24,$4 ; 48,9 ; 73,5 ; 147,3 ; 294,6 ; 441,9$; 589,2 e $736,6 \mathrm{kPa}$. Em todos os ensaios, verificou-se que as envoltórias obtidas podem ser divididas em dois segmentos de reta. Os resultados indicam que a agregação deve ser considerada na definição das cargas normais a serem utilizadas no ensaio de cisalhamento direto, bem como na análise dos resultados, pois ela tem efeitos sobre a envoltória de resistência ao cisalhamento. Para o Nitossolo Vermelho distrófico usado neste estudo, constatou-se que, na umidade em que as amostras foram ensaiadas, os agregados definem a resistência ao cisalhamento do solo para cargas normais de até $294,6 \mathrm{kPa}$.
\end{abstract}

Termos de indexação: estrutura do solo, compactação do solo, física do solo, mecânica do solo.

\footnotetext{
(1) Parte da Tese de Doutorado apresentada pelo primeiro autor ao Programa de Pós-Graduação em Ciência do Solo, Universidade Federal de Santa Maria - PPGCS/UFSM. Financiado com recursos da CAPES, CNPq e FAPERGS. Recebido para publicação em outubro de 2005 e aprovado em janeiro de 2007.

(2) Professor Adjunto, Universidade Tecnológica Federal do Paraná - UTFPR. Campus Pato Branco, Coordenação de Agronomia, CEP 85501-970 Pato Branco (PR). E-mail: braida@utfpr.edu.br

(3) Professor Adjunto, Universidade Federal de Santa Maria - UFSM. Centro de Ciências Rurais, Departamento de Solos, CEP 97105-900 Santa Maria (RS). E-mail: reichert@smail.ufsm.br e reinert@ccr.ufsm.br

(4) Professor Adjunto, Centro de Tecnologia, Departamento de Transportes, UFSM. E-mail: jmario@ct.ufsm.br
} 


\title{
SUMMARY: INTERAND INTRA-AGGREGATE STRENGTH INDIRECT SHEAR TESTS OF A TYPIC HAPLUDOX
}

\begin{abstract}
For aggregated soils the Mohr failure line can be separated into two straight lines, with different slopes and intercepts. In the range of low normal load, when the slope is very steep and the intercept is small, the failure line is defined by the friction and cohesion inter-aggregates, while for the higher load range the slope becomes smaller and intercept is larger, which defines the intra-aggregate friction and cohesion. Therefore, for aggregated soils the normal load range used in the direct shear test affects the final result. The present study was carried out with the objective of evaluating if the Mohr failure line of a Red Latosolic Nitisol can be subdivided in different segments, with different steepness and intercepts, and if this is related to the existence of soil aggregates. Initially, soil surface samples of a Typic Hapludox (Nitossolo Vermelho Distrófico latossólico, Brazilian Soil Classification System) were subjected to the direct shear test with seven normal loads $(24.4,48.9,98.2,196.4,294.6,392.8$ and $491.8 \mathrm{kPa})$. Afterwards, the tests were carried out with aggregate samples of five diameter classes $(<0.25,0.25-0.50,0.50-1.00,1.00-2.00$ and 2.00-4.00 mm) with eight normal loads (24.4, 48.9, 73.5, 147.3, 294.6, 441.9, 589.2 and $736.6 \mathrm{kPa}$ ). The Mohr failure line could be divided into two straight line segments in all tests. Results indicate that the aggregation should be considered in the definition of the normal loads to be used in the direct shear test, as well as in the result analysis, once it affects the failure line. The studies here indicate that, under the given moisture conditions, the aggregates determine the shear strength for loads of up to $294.6 \mathrm{kPa}$ for the evaluated soil.
\end{abstract}

Index terms: soil structure, soil compaction, soil physics, soil mechanics.

\section{INTRODUÇÃO}

A determinação dos parâmetros do cisalhamento de solos pode ser útil na agricultura para avaliação da capacidade de suporte (Ohu et al., 1986) e da resistência à tração do solo (Balastreire, 1987) e, conseqüentemente, no planejamento do parque de máquinas e equipamentos mais apropriados para o seu manejo; como indicador do estado de compactação (Schjonning, 1991); e na avaliação da susceptibilidade ao voçorocamento e, portanto, no estudo de técnicas que visem à estabilidade de taludes (Rocha et al., 2002).

A resistência ao cisalhamento do solo pode ser expressa pela equação de Coulomb $(\tau=c+\sigma \operatorname{tg} \phi)$, que define a envoltória de resistência ao cisalhamento do solo. Nessa equação, os parâmetros ce $\phi$ representam, respectivamente, o intercepto de coesão entre as partículas do solo e o ângulo de atrito interno. Esses parâmetros são características intrínsecas do solo, pois são dependentes de outras propriedades e características deste, como textura, estrutura, teor de matéria orgânica, densidade do solo, mineralogia e conteúdo de água (Lebert \& Horn, 1991; Schjonning, 1991; Zhang, 1994; Rocha et al., 2002).

Para solos agregados, a envoltória de resistência ao cisalhamento do solo pode ser dividida em dois segmentos, com declividades e interceptos diferentes, estando isso, segundo Lebert \& Horn (1991), relacionado à resistência dos agregados do solo. Assim, numa faixa de cargas normais menores, haveria uma primeira envoltória mais inclinada e com intercepto menor, que representaria a envoltória de ruptura definida pelo atrito e coesão interagregados (maior atrito e menor coesão), ao passo que a segunda envoltória, em uma faixa de cargas normais maiores, seria definida pelo atrito e coesão intra-agregados (menor atrito e maior coesão). O atrito e a coesão intra-agregados só se manifestariam quando os agregados fossem rompidos, ou seja, quando se empregassem tensões normais maiores que a resistência dos agregados. Carpenedo (1994) observou esse comportamento quando trabalhou com amostras de um Latossolo Roxo distrófico (Latossolo Vermelho distroférrico típico), ao passo que com amostras de um Podzólico Vermelho-Escuro (Argissolo Vermelho distrófico típico) e de um Podzólico Vermelho-Amarelo (Argissolo Vermelho distrófico arênico) isso não ocorreu. Já Gaggero (1998) observou esse comportamento quando trabalhou com amostras de um Podzólico VermelhoEscuro (Argissolo Vermelho distrófico típico).

Portanto, a faixa de tensões normais utilizadas durante a realização do ensaio de cisalhamento direto pode interferir no resultado final, o que, muitas vezes, pode levar a interpretações equivocadas sobre outros efeitos que se queira investigar. Braida (2004), ao avaliar o efeito da matéria orgânica sobre os parâmetros do cisalhamento em um Nitossolo Vermelho distrófico ( $787 \mathrm{~g} \mathrm{~kg}^{-1}$ de argila), utilizou tensões normais de 48,9; 98,2 e 196,4 kPa, obtendo ângulos de atrito interno médios de $35,1^{\circ}, 39,3^{\circ}$ e $38,6^{\circ}$, com amostras com umidade equilibrada nas tensões de 6, 100 e $500 \mathrm{kPa}$, respectivamente. Esses 
valores são relativamente altos para um solo argiloso, sendo inclusive superiores aos observados em amostras de um Argissolo Vermelho-Amarelo arênico $\left(629 \mathrm{~g} \mathrm{~kg}^{-1}\right.$ de areia) avaliado nas mesmas condições de umidade e com cargas normais de 13,$6 ; 27,3 ; 54,8 ; 148,4 ; 295,7$ e 443,0 kPa (Braida, 2004). Este autor, considerando as observações feitas por Lebert \& Horn (1991), sugere que isso possa ser explicado pelo fato de o Nitossolo apresentar, na camada superficial, estrutura pequena e forte, formada por pequenos agregados granulares muito resistentes e com superfície rugosa, algumas vezes descrita como "grumosa". Assim, é possível que as tensões normais empregadas nos ensaios com o Nitossolo não tenham sido suficientes para quebrar esses agregados, o que explicaria os elevados ângulos de atrito interno observados, enquanto no Argissolo, cuja agregação é fraca, esse tipo de efeito não teria sido observado.

Fazendo um levantamento bibliográfico sobre as cargas normais empregadas em ensaios de cisalhamento, em estudos para fins agrícolas, verificase ampla variação nos valores empregados, como se pode ver no quadro 1 . Portanto, se a amplitude das cargas normais empregadas nos ensaios pode ter efeitos sobre os resultados obtidos, a comparação desses resultados fica prejudicada.

Alguns autores que usaram número maior de cargas normais e com amplitude maior, como Secco (2002), Carpenedo (1994) e Gaggero (1998), constataram, ainda que parcialmente, a possibilidade de a envoltória de resistência ao cisalhamento ser subdividida em diferentes segmentos, como propõem Lebert \& Horn (1991), enquanto nos demais trabalhos observados isso não ocorreu ou os autores não fazem referência a esse fenômeno.

Assim, este estudo teve o objetivo de avaliar se a envoltória de resistência ao cisalhamento de um Nitossolo Vermelho distrófico latossólico pode ser subdividida em segmentos com coeficientes angulares diferentes e, se for o caso, se isso está relacionado à existência de agregados nesse solo.

\section{MATERIAL E MÉTODOS}

O presente estudo foi realizado no Laboratório de Materiais de Construção Civil (LMCC) e no Laboratório de Física do Solo da Universidade Federal de Santa Maria - UFSM, a partir de amostras de um Nitossolo Vermelho distrófico latossólico de textura argilosa, coletadas em um experimento no qual estão sendo avaliadas combinações de sistemas de manejo do solo e dos resíduos culturais e insumos orgânicos, localizado na Estação Experimental da Empresa de Pesquisa Agropecuária e Extensão Rural de Santa CatarinaEPAGRI, no município de Campos Novos, SC (Veiga, 2005). As amostras foram retiradas na profundidade de 0 a $0,03 \mathrm{~m}$. Em média, as amostras continham $787 \mathrm{~g} \mathrm{~kg}^{-1}$ de argila e $36 \mathrm{~g} \mathrm{~kg}^{-1}$ de carbono orgânico.

Quadro 1. Cargas normais, solos utilizados, teor de argila e ângulo de atrito interno médio $(\phi)$ obtidos em diversos estudos envolvendo ensaios de cisalhamento direto

\begin{tabular}{|c|c|c|c|c|}
\hline Cargas & Solo & Argila & $\phi$ Médio & Fonte \\
\hline $\mathrm{kPa}$ & & $\mathrm{g} \mathrm{kg}^{-1}$ & $\circ$ & \\
\hline \multirow[t]{3}{*}{$16 ; 30 ; 100 ; 200$ e 300} & Latossolo Vermelho distroférrico típico & 620 & 9 a 16 & Carpenedo (1994) \\
\hline & Argissolo Vermelho distrófico típico & 160 & 23 & \\
\hline & Argissolo Vermelho distrófico arênico & 80 & 23 a 32 & \\
\hline $\begin{array}{l}34,68 ; 69,37 ; 138,74 \\
277,48 \text { e } 419,22\end{array}$ & Argissolo Vermelho distrófico típico & 180 & 23 a 45 & Gaggero (1998) \\
\hline 8,$67 ; 17,34 ; 34,69$ & Latossolo Vermelho distrófico típico & 570 & 30 & Boeni (2000) \\
\hline 69,$37 ; 138,74$ & Argissolo Vermelho distrófico típico & 180 & 33 a 39 & \\
\hline \multirow[t]{5}{*}{$28 ; 42 ; 55$ e 69} & Latossolo Vermelho-Amarelo distrófico & 570 & 23,75 & Rocha et al. (2002) \\
\hline & Latossolo Vermelho distrófico & 570 & 6,30 & \\
\hline & Latossolo Vermelho distroférrico & 310 & 11,30 & \\
\hline & Argissolo Vermelho-Amarelo & 370 & 7,80 & \\
\hline & Cambissolo Háplico Tb distrófico típico & 400 & 8,97 & \\
\hline $35 ; 104 ; 208$ e 416 & Latossolo Vermelho distroférrico típico & 610 & 27,39 & $\operatorname{Secco}(2002)$ \\
\hline $\begin{array}{l}97 ; 194 ; 388 ; 776 \mathrm{e} \\
1.551\end{array}$ & Latossolo Vermelho distrófico & $\begin{array}{c}420 \text { a } \\
30\end{array}$ & 31 a 44 & Silva et al. (2004) \\
\hline $25 ; 50 ; 100 ; 200 ; 400$ e 800 & Argissolo Vermelho-Amarelo distrófico arênico & 80 & 26 a 34 & Brandt (2005) \\
\hline
\end{tabular}


Foram coletados dois conjuntos de sete monólitos indeformados, com auxílio de amostradores de secção quadrada, de tamanho compatível com a caixa de cisalhamento da prensa cisalhante utilizada $(0,05 \mathrm{~m}$ de lado e 0,02 $\mathrm{m}$ de altura), confeccionados em aço inoxidável. Essas amostras, depois de saturadas com água, tiveram suas umidades equilibradas na tensão de $500 \mathrm{kPa}$ (placa de cerâmica) e foram submetidas ao ensaio de cisalhamento direto, utilizando uma prensa de cisalhamento direto (TESTOP RONALD motorizada, permitindo diferentes velocidades de ensaio por meio de combinações de engrenagens), na qual se empregaram pressões normais de 24,$4 ; 48,9$; 98,$2 ; 196,4 ; 294,6 ; 392,8$ e $491,8 \mathrm{kPa}$.

Um segundo conjunto de ensaios foi realizado empregando-se amostras de agregados. Esses agregados foram obtidos a partir de material de solo, coletado na mesma parcela e profundidade onde foram coletados os monólitos com estrutura preservada. O material foi seco ao ar e, depois, peneirado, separandose agregados pertencentes às seguintes classes de diâmetro: < 0,25; 0,25-0,50; 0,50-1,00; 1,00-2,00 e $2,00-4,00 \mathrm{~mm}$. Os agregados foram, então, umedecidos até atingirem uma umidade gravimétrica semelhante à umidade média com que os monólitos com estrutura preservada foram testados, que foi de $0,294 \mathrm{~g} \mathrm{~g}^{-1}$. Depois de umedecidos, os agregados foram deixados em repouso durante $24 \mathrm{~h}$, em sacos plásticos fechados, para uniformizar a umidade. Os ensaios de cisalhamento direto, realizados com as amostras de agregados, empregaram pressões normais de 24,4; 48,$9 ; 73,5 ; 147,3 ; 294,6 ; 441,9 ; 589,2$ e 736,6 kPa. A mudança nos valores de algumas cargas e a ampliação do número destas teve por objetivo dar maior consistência aos resultados. Para cada pressão normal, utilizou-se uma porção de $72 \mathrm{~g}$ de agregados úmidos, colocados diretamente na caixa do aparelho de cisalhamento.

Nos ensaios de cisalhamento direto empregou-se velocidade de deslocamento horizontal de $4,1710^{-6} \mathrm{~m} \mathrm{~s}^{-1}$, com deslocamento horizontal máximo de $0,015 \mathrm{~m}$. As cargas normais foram aplicadas cinco minutos antes de se iniciar efetivamente o ensaio de cisalhamento. Assim, para cada tensão normal empregada, em cada amostra, obteve-se um valor de tensão de cisalhamento. Com esses dados, foram calculados os parâmetros de resistência ao cisalhamento, intercepto de coesão e ângulo de atrito interno, conforme proposto por Lambe \& Witman (1979). Entretanto, antes do ajuste das equações, utilizando-se uma planilha eletrônica, os dados obtidos com cada amostra foram plotados em um gráfico e fez-se uma avaliação da possibilidade de a envoltória de cisalhamento obtida ser subdividida em segmentos de reta com coeficientes angulares diferentes, de acordo com o proposto por Lebert \& Horn (1991). Constatada essa possibilidade, ajustou-se uma equação para cada segmento de reta. $\mathrm{O}$ valor da resistência dos agregados $(\mathrm{R})$ foi estimado conforme proposto por Lebert \& Horn (1991), correspondendo à tensão normal no ponto de interseção

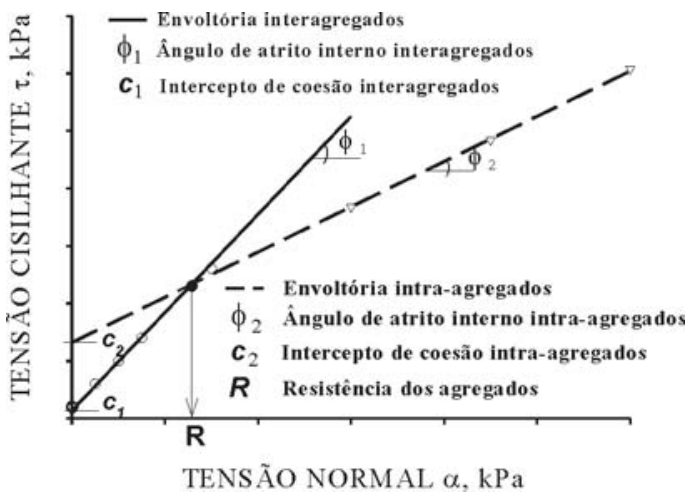

Figura 1. Determinação da resistência dos agregados do solo (R), a partir da definição das envoltórias de resistência ao cisalhamento interagregados e intra-agregados, conforme proposto por Lebert \& Horn (1991).

entre a envoltória de cisalhamento interagregados e a envoltória de cisalhamento intra-agregados, conforme demonstrado na figura 1.

\section{RESULTADOS E DISCUSSÃO}

As envoltórias de resistência ao cisalhamento, obtidas nos ensaios de cisalhamento direto com amostras de estrutura preservada e com amostras de agregados, são mostradas na figura 2 , em que se observa a existência de duas envoltórias distintas para cada situação estudada. Comportamento semelhante foi observado por Carpenedo (1994) e Gaggero (1998) em ensaios com um Latossolo Roxo e um Podzólico Vermelho-Escuro, respectivamente.

No presente caso, para todas as amostras, a primeira envoltória compreende pressões normais de até $294,6 \mathrm{kPa}$, enquanto a segunda se manifesta para pressões normais iguais ou superiores a esse valor (Figura 2). Segundo Lebert \& Horn (1991), a pressão normal correspondente ao ponto de interseção da primeira com a segunda envoltória é igual à resistência dos agregados do solo. Por isso, quando se utilizam cargas normais menores que esse valor, os agregados permanecem intactos e a envoltória é definida pela coesão e pelo atrito entre estes, resultando em um ângulo de atrito maior, em razão da rugosidade superficial e do tamanho dos agregados, e em um intercepto de coesão menor, já que o número de pontos de contato e a força das ligações nesses pontos são menores do que nos espaços intra-agregados (Baumgartl \& Horn, 1991). Quando se aplicam pressões normais maiores que a resistência dos agregados, estes se rompem e a envoltória de cisalhamento passa a ser definida por coesão e atrito entre as partículas primárias do solo. Nesse caso, o intercepto de coesão é maior, em razão da maior interação entre as partículas primárias, e o ângulo de atrito interno é menor, devido à reduzida rugosidade e ao menor tamanho das partículas (Lebert \& Horn, 1991). 

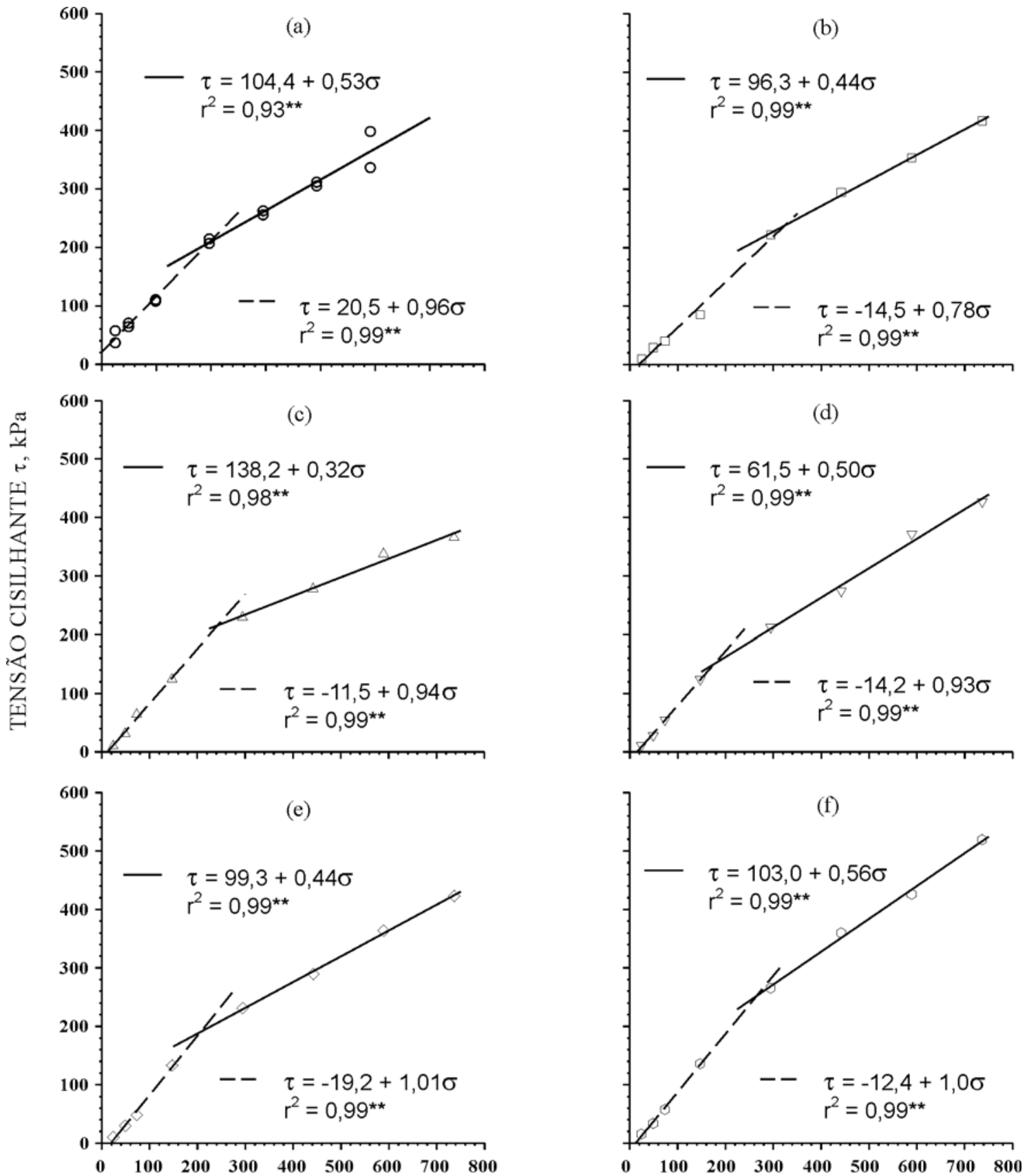

TENSÃO NORMAL $\alpha, \mathrm{kPa}$

Figura 2. Envoltórias de resistência ao cisalhamento interagregados (--) e intra-agregados (--) de agregados do horizonte superficial de um Nitossolo Vermelho distrófico latossólico, para amostras de: (a) solo com estrutura preservada; (b) agregados com diâmetro < 0,25 mm; (c) agregados com diâmetro entre 0,25 e $0,50 \mathrm{~mm}$; (d) agregados com diâmetro entre 0,50 e 1,00 mm; (e) agregados com diâmetro entre 1,00 e $2,00 \mathrm{~mm}$; e (f) agregados com diâmetro entre 2,00 e $4,00 \mathrm{~mm}$.

Visualmente, observando fotos da superfície de ruptura das amostras submetidas ao ensaio de cisalhamento (Figura 3), verifica-se que nas pressões menores $(24,4$ e $73,5 \mathrm{kPa})$ a superfície de cisalhamento ainda mostra uma rugosidade determinada pelos agregados, ao passo que nas maiores isso não acontece, especialmente naquelas maiores que $294,6 \mathrm{kPa}$. Nas maiores pressões, a fricção produziu orientação das partículas de argilas, tornando a superfície de cisalhamento espelhada, de acordo com a orientação das partículas de argila, confirmando que nessa situação ocorre atrito entre partículas primárias do solo. 
Os valores do intercepto de coesão e do ângulo de atrito interno inter e intra-agregados e a resistência dos agregados (Quadro 2), estimados conforme Lebert \& Horn (1991), corroboram as observações desses autores e confirmam que os agregados do solo podem estar influenciando, de maneira significativa, sua envoltória de resistência ao cisalhamento.

Conforme pode ser observado nas equações da figura 2 , os valores ajustados do intercepto de coesão interagregados, para as amostras de agregados, foram sempre negativos. Nesses casos, considerando que não existe coesão negativa, assumiu-se que a coesão é nula e, por isso, no quadro 2, para estas amostras, o intercepto de coesão apresentado é igual a zero. Essa suposição é sustentada no fato de que, nesses casos, os ensaios foram realizados com agregados soltos colocados diretamente na caixa do aparelho de cisalhamento direto e que, portanto, não apresentavam coesão significativa. Nas amostras com estrutura preservada, observou-se valor de intercepto de coesão interagregados $(20,5 \mathrm{kPa})$ cerca de cinco vezes menor do que aquele observado no intercepto de coesão intraagregados $(104,4 \mathrm{kPa})$, provavelmente pela proximidade entre as partículas e pelo maior número e tipo de pontos de contatos existentes nos espaços intra-agregados (Baumgartl \& Horn, 1991). O ângulo de atrito interno interagregados médio obtido com as amostras de agregados foi, numericamente, semelhante ao obtido com as amostras com estrutura preservada (Quadro 2).

Os valores médios do intercepto de coesão e do ângulo de atrito interno intra-agregados, obtidos a partir dos ensaios com os agregados, foram semelhantes aos das amostras com estrutura preservada (Quadro 2). Deve-se considerar que as diferenças observadas podem ser devidas ao fato de que, no solo, cada classe de agregados contribui de forma e magnitude diferentes para determinação do $\phi$ e da $c$, enquanto no cálculo da média, aqui realizado, essas diferenças não foram consideradas. Isso justificaria, ainda, as diferenças observadas na resistência dos agregados (Quadro 2). Nesse caso,

Quadro 2. Intercepto de coesão (c) e ângulo de atrito interno ( $\phi)$, inter e intra-agregados, e resistência dos agregados $(R)$ de um Nitossolo Vermelho distrófico latossólico, determinados em amostra de solo com estrutura preservada e em amostras de agregados de cinco classes de tamanho

\begin{tabular}{|c|c|c|c|c|c|c|c|}
\hline \multirow{2}{*}{ Tipo de amostra } & \multirow{2}{*}{$\mathbf{U g}$} & \multirow{2}{*}{ Argila } & \multicolumn{2}{|c|}{ Interagregados } & \multicolumn{2}{|c|}{ Intra-agregados } & \multirow{2}{*}{$\mathbf{R}^{(1)}$} \\
\hline & & & $c$ & $\phi$ & $c$ & $\phi$ & \\
\hline & $\mathrm{g} \mathrm{g}^{-1}$ & $\mathrm{~g} \mathrm{~kg}^{-1}$ & $\mathrm{kPa}$ & $\circ$ & $\mathrm{kPa}$ & $\circ$ & $\mathrm{kPa}$ \\
\hline Agregados: $<0,25 \mathrm{~mm}$ & 0,314 & 797 & 0 & 37,9 & 96,3 & 23,6 & 324,3 \\
\hline Agregados: $0,25-0,50 \mathrm{~mm}$ & 0,313 & 793 & 0 & 43,1 & 138,2 & 17,7 & 242,8 \\
\hline Agregados: $0,50-1,00 \mathrm{~mm}$ & 0,294 & 805 & 0 & 43,0 & 61,5 & 26,7 & 176,9 \\
\hline Agregados: $1,00-2,00 \mathrm{~mm}$ & 0,304 & 794 & 0 & 45,4 & 99,3 & 23,8 & 206,5 \\
\hline Agregados: $2,00-4,00 \mathrm{~mm}$ & 0,289 & 769 & 0 & 44,9 & 103,0 & 29,3 & 265,9 \\
\hline Média & 0,303 & 792 & 0 & 43,0 & 99,7 & 24,3 & 243,3 \\
\hline Solo com estrutura preservada & 0,294 & 787 & 20,5 & 43,7 & 104,4 & 27,9 & 196,7 \\
\hline
\end{tabular}

(1) Estimado segundo Lebert \& Horn (1991).

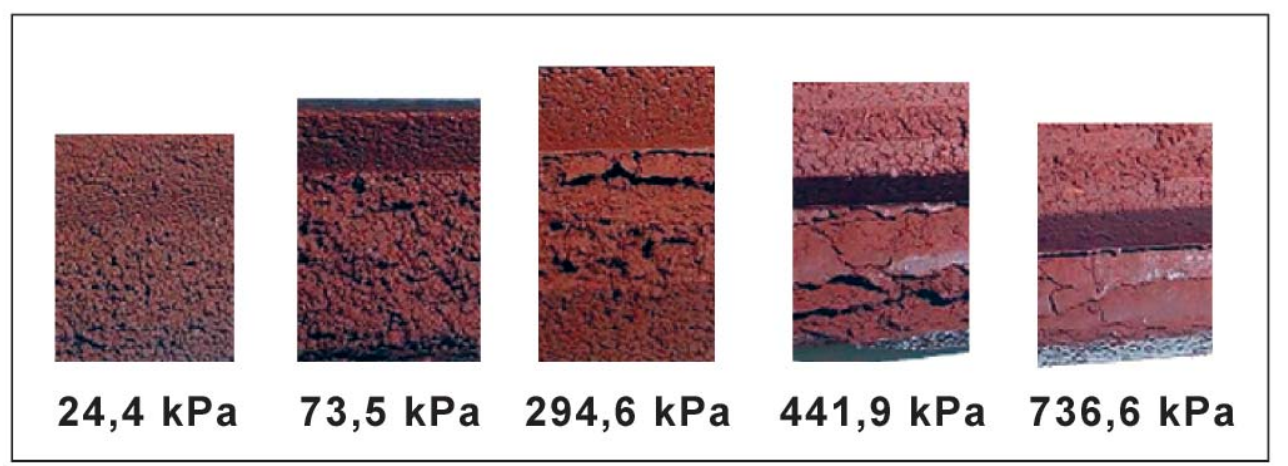

Figura 3. Imagens da superfície de ruptura de amostras de agregados com diâmetro de 1,00 a 2,00 mm, submetidas ao ensaio de cisalhamento direto com cargas de 24,$4 ; 73,5 ; 294,6 ; 441,9$ e 736,6 kPa (escala aproximada $1: 1)$. 
deve-se considerar, também, que o processo de obtenção dos agregados, peneiramento a seco, pode ter contribuído para seleção de agregados mais resistentes, especialmente nas classes de maior tamanho, o que não ocorre quando se empregam amostras com estrutura preservada.

As diferenças observadas nos parâmetros do cisalhamento entre as diferentes classes de tamanho de agregados se devem, provavelmente, a diferenças nos mecanismos de agregação, no teor e tipo de matéria orgânica, no conteúdo de água e a diferenças texturais entre os agregados de cada classe de tamanho, que são as características envolvidas na determinação da resistência ao cisalhamento do solo (Lebert \& Horn, 1991; Schjonning, 1991; Zhang, 1994; Rocha et al., 2002).

Todavia, esses resultados confirmam que os parâmetros da resistência ao cisalhamento obtidos nos ensaios podem ser diferentes, dependendo da magnitude das cargas normais empregadas na sua realização. Para o solo em questão e nas condições de umidade avaliadas, ensaios com carga normal máxima de 294,6 kPa podem ser considerados como relativos aos espaços interagregados, ou ao menos estarem sob forte influência das forças de coesão e do atrito existentes nesses espaços. Assim, para obter os valores do intercepto de coesão e do ângulo de atrito interno referentes às partículas primárias desse solo, na umidade aqui trabalhada, deveriam ser empregadas somente cargas normais superiores a $294,6 \mathrm{kPa}$.

Além disso, como sugerem Lebert \& Horn (1991), os resultados aqui apresentados confirmam que o ensaio de cisalhamento direto pode ser usado na determinação da resistência média dos agregados da massa do solo, bastando que se empreguem número e amplitude de cargas normais suficientes para que se possam calcular as envoltórias de cisalhamento interagregados e intra-agregados.

\section{CONCLUSÕES}

1. Os resultados confirmam que a envoltória de resistência ao cisalhamento do solo pode ser subdividida em segmentos com coeficientes angulares diferentes e que isso está relacionado à existência de agregados nesse solo.

2. Para as condições de umidade e solo (Nitossolo Vermelho distrófico) deste estudo, os agregados definem a resistência ao cisalhamento do solo para cargas normais de até $294,6 \mathrm{kPa}$.

3. A agregação deve ser considerada na definição das cargas normais a serem utilizadas no ensaio de cisalhamento direto, bem como na análise dos resultados obtidos.

\section{LITERATURA CITADA}

BALASTREIRE, L.A. Máquinas agrícolas. São Paulo, Manole, 1987. 310p.

BAUMGARTL, T. \& HORN, R. Effect of aggregate stability on soil compaction. Soil Till. Res., 19:203-213, 1991.

BOENI, M. Comportamento mecânico de solos escarificados em função do teor de água e pressão de inflação dos pneus do trator. Porto Alegre, Universidade Federal do Rio Grande do Sul, 2000. 99p. (Tese de Mestrado)

BRANDT, A.A. Propriedades mecânicas de solo franco arenoso sob distintos sistemas de preparo, tráfego mecanizado e resíduos vegetais. Santa Maria, Universidade Federal de Santa Maria, 2005. 89p. (Tese de Mestrado)

BRAIDA, J.A. Matéria orgânica e resíduos vegetais na superfície do solo e suas relações com o comportamento mecânico do solo sob plantio direto. Santa Maria, Universidade Federal de Santa Maria, 2004. 107p. (Tese de Doutorado)

CARPENEDO, V. Compressibilidade de solos em sistemas de manejo. Porto Alegre, Universidade Federal do Rio Grande do Sul, 1994. 106p. (Tese de Doutorado)

GAGGERO, M.R. Alterações das propriedades físicas e mecânicas do solo sob sistemas de preparo e pastejo. Porto Alegre, Universidade Federal do Rio Grande do Sul, 1998. 125p. (Tese de Mestrado)

LAMBE, T.W. \& WHITMAN, R.V. Soil mechanics. New York, J. Wiley \& Sons, 1979. 553p. (Series in Soil Engineering)

LEBERT, M. \& HORN, R. A method to predict the mechanical strength of agricultural soils. Soil Till. Res., 19:275-286, 1991.

OHU, O.J.; RAGHAVAN, G.S.V.; MCKYES, E. \& MEHUYS, G. Shear strength prediction of soils with varying added organic matter contents. Trans. Am. Sci. Agric. Eng., 29:351-355, 1986.

ROCHA, W.W.; DIAS JUNIOR, M.S.; LIMA,J.M.; MIRANDA, E.E.V. \& SILVA, A.R. Resistência ao cisalhamento e grau de intemperismo de cinco solos na região de Lavras (MG). R. Bras. Ci. Solo, 26:297-303, 2002.

SCHJONNING, P. Soil strength as influenced by texture, water content and soil management. Soil Till. Res., 12:277$283,1991$.

SECCO, D. Estados de compactação de dois Latossolos sob plantio direto e suas implicações no comportamento mecânico e na produtividade de culturas. Santa Maria, Universidade Federal de Santa Maria, 2003. 105p. (Tese de Doutorado)

SILVA, R.B.; DIAS JUNIOR, M.S.; SANTOS, F.L.\& FRANZ, C.A.B. Resistência ao cisalhamento de um Latossolo sob diferentes uso e manejo. R. Bras. Ci. Solo, 28:165-173, 2004. 
VEIGA, M. Soil properties after nine years use of soil management systems and effect on crop production. Santa Maria, Universidade Federal de Santa Maria, 2005. 110p. (Tese de Doutorado)
ZHANG, H. Organic matter incorporation affects mechanical properties of soil aggregates. Soil Till. Res., 31:263-275, 1994. 